\title{
Rapid Antidepressant Action and Restoration of Excitatory Synaptic Strength After Chronic Stress by Negative Modulators of Alpha5-Containing $\mathrm{GABA}_{\mathrm{A}}$ Receptors
}

\author{
Jonathan Fischell ${ }^{1,2}$, Adam M Van Dyke ${ }^{\text {I,3,4, Mark D Kvarta }}{ }^{1,3,4,5}$, Tara A LeGates' and Scott M Thompson ${ }^{*, 1,6}$ \\ 'Department of Physiology, University of Maryland School of Medicine, Baltimore, MD, USA; ${ }^{2}$ Program in Molecular Medicine, University of \\ Maryland School of Medicine, Baltimore, MD, USA; ${ }^{3}$ Program in Neuroscience, University of Maryland School of Medicine, Baltimore, MD, USA; \\ ${ }^{4}$ Program in Membrane Biology, University of Maryland School of Medicine, Baltimore, MD, USA; ${ }^{5}$ Medical Scientist Training Program, University of \\ Maryland School of Medicine, Baltimore, MD, USA; ${ }^{6}$ Department of Psychiatry, University of Maryland School of Medicine, Baltimore, MD, USA
}

\begin{abstract}
Selective serotonin reuptake inhibitors (SSRIs) are the primary pharmacological treatment for depression, but SSRIs are effective in only half of the patients and typically take several weeks to relieve symptoms. The NMDA receptor antagonist ketamine exerts a rapid antidepressant action, but has troubling side effects. We hypothesized that negative allosteric modulators of GABA $\mathrm{A}_{\mathrm{r}}$ receptors would exert similar effects on brain activity as ketamine, but would not exert as many side effects if targeted only to GABA $A$ receptors containing $\alpha 5$ subunits, which are enriched in the hippocampus and prefrontal cortex. Here, we show that the $\alpha 5$-selective negative modulator L-655,708 reversed the alterations in hedonic behavior in the sucrose preference and social interaction tests produced by two different chronic stress paradigms in rats within $24 \mathrm{~h}$ of systemic administration. Similar effects were observed with another $\alpha 5$-selective negative modulator, MRK-0 16. L-655,708 had no effect on hedonic or open-field behavior in unstressed animals. Within 24 h, L-655,708 injection also restored the strength of pathologically weakened excitatory synaptic transmission at the stress-sensitive temporoammonic-CAI synapse, measured electrophysiologically, and increased levels of the GluAI subunit of the AMPA receptor, measured with western blotting. We suggest that the ability of L-655,708 to restore excitatory synaptic strength rapidly may underlie its ability to restore stressinduced behavioral alterations rapidly, supporting evidence that dysfunction of multiple excitatory synapses in cortico-mesolimbic reward pathways contributes, in part, to the genesis of depression. Negative allosteric modulators of $\alpha 5$ subunit-containing $G_{A B A}$ receptors represent a promising novel class of fast-acting and clinically viable antidepressant compounds.

Neuropsychopharmacology (2015) 40, 2499-2509; doi:I 0.I038/npp.20I5.I I2; published online I 3 May 2015
\end{abstract}

\section{INTRODUCTION}

The present standard of care for treating major depressive disorder is to increase the concentration of monoamine neurotransmitters by inhibiting their reuptake with medications such as selective serotonin reuptake inhibitors (SSRIs). SSRIs are fully effective in only half of the depressed patients (Gaynes and Warden, 2009), however. In addition, the 3-8 week latency to achieve a therapeutic effect complicates optimization of medication and delays symptomatic relief. More effective and faster-acting therapies are clearly needed to reduce the socioeconomic burden of this debilitating condition.

The discovery that inhibitors of NMDA-type glutamate receptors (NMDARs), such as ketamine, exert a rapid antidepressant action (Trullas and Skolnick, 1990; Berman

\footnotetext{
*Correspondence: Dr SM Thompson, Department of Physiology, University of Maryland School of Medicine, 655 West Baltimore Street, Baltimore, MD 21201, USA, Tel: +410 706 5817, Fax: +4I0 706 834I, E-mail: sthom003@umaryland.edu

Received 9 December 2014; revised 8 April 2015; accepted 8 April 2015; accepted article preview online 22 April 2015
}

et al, 2000; Zarate et al, 2006) has triggered a reevaluation of the causes of depression and potential targets for antidepressants. Unfortunately, there are concerns that ketamine's addictive and psychotomimetic properties will hinder it from reaching its potential to treat human depression (Machado-Vieira et al, 2009). Ketamine also produces a rapid antidepressant-like behavioral response in rodents subjected to chronic stress (Maeng et al, 2008; Li et al, 2010; 2011; Autry et al, 2011). This has provided critical mechanistic insights into how rapid antidepressant actions may be produced and raised hopes that new drugs can be developed that target the same effector mechanisms, without ketamine's disadvantages.

A common element linking the therapeutic actions of antidepressants, including SSRIs (Cai et al, 2013), ketamine (Pittenger and Duman, 2008; Kavalali and Monteggia, 2012; Abdallah et al, 2014), and scopolamine (Voleti et al, 2013), is their shared effects on excitatory synapses in corticomesolimbic reward circuits (Thompson et al, 2015). Chronic stress produces depression-like changes in behavior, as well as deleterious effects on excitatory synaptic structure and function, in multiple brain regions that are associated with 
cognition, reward, and mood, including the hippocampus (McEwen, 2000; Kallarackal et al, 2013), prefrontal cortex (PFC) (Yuen et al, 2012; Pittenger and Duman, 2008), and nucleus accumbens (NAc) (Lim et al, 2012). Conversely, ketamine, serotonin, and SSRIs promote excitatory synaptic transmission and reverse the effects of chronic stress in these same areas (Pittenger and Duman, 2008; Li et al, 2010; Autry et al, 2011; Cai et al, 2013).

Although the mechanisms underlying ketamine's rapid antidepressant action remain under active investigation, one hypothesis is that it suppresses NMDAR-mediated excitation of inhibitory interneurons (Moghaddam et al, 1997; Farber et al, 1998; Homayoun and Moghaddam, 2007; Abdallah et al, 2014; cf. however, Autry et al, 2011). This results in a mild disinhibition of the neuronal population. Presumably because of this increase in network activity, a brief period of ketamine administration triggers several activity-dependent processes, such as induction of long-term potentiation, increased expression of the immediate early gene $\Delta \mathrm{FosB}$, and altered activity of the mTOR and/or eEF2 signaling pathways. This ultimately leads to the rapid induction of synapse-related genes, increased synthesis of synaptic proteins (Li et al, 2010; Autry et al, 2011; Duman and Voleti, 2012), restoration of normal synaptic strength, and persistent amelioration of depressive signs and symptoms. These results suggest that it is ultimately the mild increase in activity in forebrain neural circuits that is the key mechanism via which ketamine exerts its rapid therapeutic antidepressant actions.

On the basis of this model, we sought to identify other compounds that could trigger mild increases in neuronal activity, like ketamine. Partial inverse agonists at the benzodiazepine binding site of $\gamma$-aminobutyric acid type-A receptors $\left(\mathrm{GABA}_{\mathrm{A}} \mathrm{Rs}\right)$ are negative allosteric modulators that have been shown to promote coherent network activity (Hajós et al, 2004). $\mathrm{GABA}_{\mathrm{A}} \mathrm{Rs}$ containing the $\alpha 5$-subunit are most strongly expressed by prefrontal cortical neurons and hippocampal pyramidal cells, offering the potential means for selectively targeting cortical inputs to mesolimbic circuits, thereby potentially minimizing psychotomimetic and sedative side effects. L-655,708 and MRK-016 are negative allosteric modulators of $\mathrm{GABA}_{\mathrm{A}}$ Rs with a $10-100$ fold selectivity for $\mathrm{GABA}_{\mathrm{A}} \mathrm{Rs}$ containing the $\alpha 5$-subunit (Atack et al, 2005; 2006; 2009). The $\alpha 5$-selective negative allosteric modulators are not epileptogenic, hallucinogenic, or anxiogenic in humans (Atack et al, 2009).

We hypothesized that L-655,708 and MRK-016 would exert a rapid antidepressant action via convergence on ketamine's downstream effector mechanisms, and therefore predicted that a single treatment of these compounds would rapidly $(<24 \mathrm{~h})$ reverse chronic stress-induced changes in both hedonic behavior and excitatory synaptic transmission at the archetypical stress-sensitive synapse between temporoammonic (TA) afferents and the distal dendrites of CA1 pyramidal cells.

\section{MATERIALS AND METHODS}

\section{Chronic Restraint Stress (CRS)}

Male Sprague Dawley rats (5-6 weeks-old; Harlan Laboratories) were placed in appropriately sized restraint tubes, highly restricting their movement for periods of 4 hours in a brightly lit lab, every day for 10 days during the light phase of their diurnal cycle (Lim et al, 2012).

\section{Chronic Unpredictable Stress (CUS)}

Male Sprague-Dawley rats (5-6 weeks-old; Harlan Laboratories) were randomly divided into control and CUS groups. Rats in the CUS group were individually housed. CUS animals were treated with two mild stressors every day for 5-6 weeks during their light phase (Willner et al, 1987). The stressors were randomly cycled to enhance unpredictability. The stressors were: forced swim, in which rats were placed in a basin containing cold water for $5 \mathrm{~min}$; strobe lighting, in otherwise total darkness for $30 \mathrm{~min}$; restraint, during which rats were put into appropriately sized restraint tubes for $30 \mathrm{~min}$; exposure to white noise for $30 \mathrm{~min}$; and food or water deprivation for $14 \mathrm{~h}$ spanning the dark phase.

\section{Sucrose Preference Test (SPT)}

Rats were given a choice between two bottles containing tap water or $1 \%$ sucrose solution (Rygula et al, 2006). Testing was conducted overnight $(16 \mathrm{~h})$, including the full duration of their dark phase. Animals were first trained with both bottles while group-housed. For subsequent tests, including during the baseline period, animals were individually housed. Sucrose preference was calculated as the percentage of the sucrose solution consumed to the total amount of fluid consumed. For determining the effects of L-655,708 and MRK-016, only unstressed rats that demonstrated a sucrose preference $>65 \%$ at baseline were used.

\section{Social Interaction Test (SIT)}

As described previously (Zelena et al, 1999; Berton et al, $2006)$, rats were placed in a plastic enclosure $(82 \times 82 \mathrm{~cm})$ with a $5 \times 5$ grid of squares $(16.4 \times 16.4 \mathrm{~cm})$ visible underneath the clear plastic flooring. A small translucent perforated plastic box $(20 \times 16 \mathrm{~cm})$ was placed against the center of one wall of the arena. During the testing conditions, white overhead fluorescent lighting was used to illuminate the arena. A video camera positioned $170 \mathrm{~cm}$ above the floor of the arena was used to track the movements of the rats during the experiment.

Each test consisted of a 'target-absent' trial followed by a 'target-present' trial. During testing, an individual test rat was placed in the center of the arena and, after $30 \mathrm{~s}$ of adaptation, the rat's movements were recorded with the video camera for $2.5 \mathrm{~min}$. After the 'target-absent' trial, the test rat was removed from the arena and placed back in its home cage. For the 'target-present' trial, a novel juvenile (3-6 weeks old; always younger than the rat being tested) rat was placed in the internal box at one end of the arena and, after 3 minutes, the test rat was returned to the center of the arena and filmed for $2.5 \mathrm{~min}$. Both rats were removed and the testing arena and internal box were cleaned with $70 \%$ ethanol before the next rat was tested. No test rat ever encountered the same target rat more than once.

Results were quantified as the percentage of time spent in the 'interaction zone' (the five grid squares immediately surrounding the plastic cage) as measured for both the 'target-absent' and 'target-present' trials. These percentages 
were then used to calculate an interaction ratio, which is the percent time spent in the 'interaction zone' during the 'target-present' trial divided by that of the 'target-absent'. For determining the effects of L-655,708 and MRK-016, only unstressed rats that demonstrated a social interaction ratio $>100$ at baseline were used.

\section{Open Field}

Open-field behavior was monitored in the $82 \times 82 \mathrm{~cm}$ arena with the $5 \times 5$ grid of 16 outer squares and 9 inner squares placed in a dimly lit room during the rats' light cycle. Rats were placed in one corner of the arena and filmed for post hoc analysis. The observer recorded the crossings into inner or outer squares within a 5-min test session. The data were analyzed for total number of crossings from one square to another inner or outer square, from which the total number of crossings into inner squares were calculated.

\section{Acute Slice Electrophysiology}

Standard methods were used to prepare $400-\mu$ m-thick transverse hippocampal slices. Dissection and recording saline contained: $124 \mathrm{mM} \mathrm{NaCl}, 3 \mathrm{mM} \mathrm{KCl}, 1.25 \mathrm{mM}$ $\mathrm{NaH}_{2} \mathrm{PO}_{4}, 1.5 \mathrm{mM} \mathrm{MgSO}_{4}, 2.5 \mathrm{mM} \mathrm{CaCl}_{2}, 26 \mathrm{mM} \mathrm{NaHCO}_{3}$, and $10 \mathrm{mM}$ glucose, bubbled with $95 \% \mathrm{O}_{2} / 5 \% \mathrm{CO}_{2}$. Slices were then transferred to a submersion-type recording chamber and perfused at $0.5-2 \mathrm{ml} / \mathrm{min}$ at $20-22^{\circ} \mathrm{C}$. Picrotoxin $(100 \mu \mathrm{M})$ and CGP52432 $(2 \mu \mathrm{M})$ were included to block $\mathrm{GABA}_{\mathrm{A}}$ and $\mathrm{GABA}_{\mathrm{B}}$ receptors, and the CA3 region was removed with a scalpel. Because TA-CA1 synapses are electrotonically remote from CA1 cell somata, we used extracellular recording of local field excitatory postsynaptic potentials (fEPSPs). Recording pipettes (3-5 M $\Omega$ ) contained extracellular saline and were placed in stratum lacunosummoleculare (SLM) to record TA-CA1 responses. fEPSPs were amplified $\times 1000$, filtered at $3 \mathrm{kHz}$, and digitized at $10 \mathrm{kHz}$. Concentric bipolar tungsten electrodes were placed $>500 \mu \mathrm{m}$ from the stimulating electrodes in SLM for TA afferents. Stimuli $(100 \mu \mathrm{s})$ were delivered at $0.05 \mathrm{~Hz}$.

As in our previous work (Kallarackal et al, 2013), $\mathrm{Mg}^{2+}$-free saline was used to produce a robust NMDARmediated component of the fEPSP for quantification of AMPAR-mediated synaptic excitation. 3-5 consecutive responses were averaged and fEPSP slope was calculated over a 1-3 ms window. For AMPAR-mediated responses, the window was fixed in the initial rising phase of the response, 2-5 ms after its initiation. For NMDA responses, DNQX $(50 \mu \mathrm{M})$ was bath applied for $15 \mathrm{~min}$ and the slope was calculated over a $3-5 \mathrm{~ms}$ window in the rising phase of the response, 5-10 $\mathrm{ms}$ after its initiation.

Responses were elicited over a range of stimulation intensities before and after application of DNQX. We first compared responses across slices by normalizing them to the amplitude of the fiber volley. The linear portion of the relationship between response slope and FV amplitude was fit with a straight line and the slopes of the fitted lines were compared across conditions, as we have done previously (Kallarackal et al, 2013). We also normalized the slope of AMPAR-mediated responses to the slope of the NMDARmediated response, choosing traces that had a fiber volley closest to $0.2 \mathrm{mV}$ in amplitude.

\section{Western Blotting}

SLM tissue punches ( $1 \mathrm{~mm}$ diameter) were dissected from area CA1 in hippocampal slices and pooled (3-4 punches/ sample). Membranes were probed with antibodies directed against GluA1 (Millipore Bioscience Research Reagents) and $\beta$-actin (Cell Signaling Technology). Levels of proteins are expressed as the ratio of intensity normalized to $\beta$-actin intensity, as done previously (Kallarackal et al, 2013).

\section{Drugs/Stats}

L-655,708 was purchased from Tocris Bioscience (R\&D Systems, Minneapolis, MN) and prepared at a concentration of $5 \mathrm{mM}$ in $75 \%$ saline/25\% DMSO. The dose used in this study $(0.7 \mathrm{mg} / \mathrm{kg}$ i.p.) was taken from the study of Martin et al (2009), in which L-655,708 was shown to reverse the amnestic properties of the anesthetic etomidate; a positive sign of its efficacy in brain. This dose is sufficient to occupy $\sim 70 \%$ of forebrain binding sites (Atack et al, 2005). MRK-016 (Tocris Bioscience) was dissolved in DMSO at $6 \mathrm{mg} / \mathrm{ml}$.

All quantification and analyses of behavioral, electrophysiological, and western blotting results were performed with the experimenter masked to the condition of the animal, tissue, or protein sample. Data were first compared with an analysis of variance, followed by pairwise post hoc comparison tests using SPSS software.

\section{RESULTS}

\section{Rapid Reversal of Stress-Induced Changes in Hedonic Behavior by L-655,708}

Several hedonic behaviors in rodents are sensitive to chronic stress and are restored by chronic, but not acute, administration of SSRIs, providing one means to screen for potential antidepressant compounds. We first sought to determine whether L-655,708 would rapidly $(<24 \mathrm{~h})$ restore normal hedonic behavior following chronic restraint stress (Watanabe et al, 1992; Lim et al, 2012), consistent with the rapid antidepressant-like actions of ketamine (Li et al, 2011). We first made baseline measurements of social interaction and sucrose preference, and then subjected 5-6-week-old rats to 10 days of CRS. At the culmination of CRS treatment, rats were injected with either vehicle (75\% saline, $25 \%$ DMSO; i.p.) or L-655,708 (0.7 mg/kg, i.p.). Social interaction and sucrose preference tests were then repeated $24 \mathrm{~h}$ post injection. Chronic restraint stress produced a decrease in social interaction ratio in vehicle-injected CRS rats compared with all other groups, whereas the social interaction ratio in the L-655,708-injected rats was not significantly different than baseline $(\mathrm{F}(1,12)=2.85, \quad p=0.115 ; n=7$ vehicleinjected, 7 L-655,708 injected; Figure 1a). Similarly, there was a significant decrease in sucrose preference in stressed rats that received a vehicle injection compared with their pre-stress baseline, whereas stressed rats administered L-655,708 showed levels of sucrose preference that were not different from their pre-stress baseline $(\mathrm{F}(1,11)=7.514$, $p=0.019$; Figure $1 \mathrm{~b}$ ). These behavioral changes are consistent with previous descriptions of chronic SSRIs (Cai et al, 2013) and acute ketamine (Li et al, 2011). 

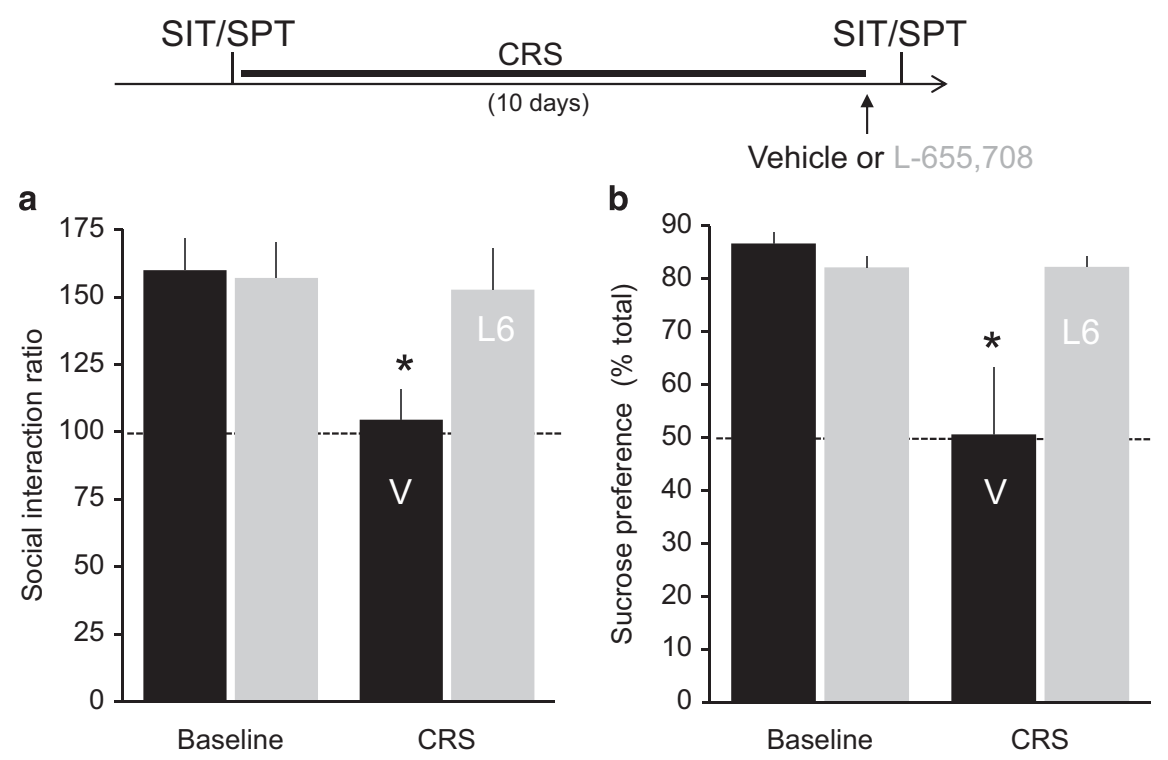

Figure I L-655,708 rapidly reverses loss of sucrose preference and social interaction behaviors after chronic restraint stress (CRS). Quantification of results from the (a) social interaction (SIT, left) and (b) sucrose preference tests (SPT, right) at two time points: before CRS and after 10 days of CRS. $24 \mathrm{~h}$ before the second round of tests, rats received an injection of either vehicle (black) or L-655,708 (gray). Mean social interaction ratios differed significantly following vehicle injection compared with all other groups $(F(I, I 2)=2.85, p=0.115 ; n=7$ CRS+vehicle rats, 7 CRS+L-655,708 rats). Mean sucrose preference differed significantly following vehicle injection compared with all other groups $(2 \times 2$ repeated-measures ANOVA group-time interaction $F(I, I I)=7.5 \mid 4, p=0.0$ I 9$)$. $* p<0.05$ compared with pre-CUS baseline, Bonferroni post hoc test; $n=7$ CRS+vehicle rats, 6 CRS $+L-655,708$ rats). The dashed line in both graphs indicates the value at which there is no preference for social interaction or the sucrose solution in this and all graphs.

To determine whether the rapid reversal of stress-induced changes in behavior by L-655,708 was specific to the CRS procedures, we repeated these experiments using another chronic psychological stress paradigm, chronic unpredictable stress (CUS, Willner et al, 1987). Social interaction tests were conducted at three sequential time points (Figure 2): before CUS (baseline), after 4 weeks of CUS and an injection of the vehicle solution $24 \mathrm{~h}$ earlier, and after an additional week of CUS and an injection of L-655,708 $24 \mathrm{~h}$ earlier $(0.7 \mathrm{mg} / \mathrm{kg}$, i.p.). The mean social interaction ratio was significantly lower in rats subjected to CUS that were given a vehicle injection compared with their baseline values $(\mathrm{F}(2,34)=15$, $p<0.0001$; vehicle-treated group $p<0.01$ vs baseline and L-655,708, Tukey's; $n=18$ rats; Figure 2a), consistent with previous descriptions of stress-induced behavioral changes in mice (Berton et al, 2006). Twenty-four hours after a single injection of L-655,708, social interaction in 14 of 18 CUS rats were reversed to levels that were not significantly different than pre-stress baseline or responses in unstressed animals (Figure 2b, black symbols). The four CUS rats injected with L-655,708 that failed to display an increase in social interaction appeared largely resilient to the CUS procedures (Figure 2b, gray symbols). Unstressed rats displayed no significant difference in either sucrose preference or social interaction $24 \mathrm{~h}$ after injection with $\mathrm{L}-655,708$ or saline (Figure $2 \mathrm{c}$ and $\mathrm{d}$ ).

Similarly, a single injection of L-655,708 restored sucrose preference in rats subjected to CUS $(\mathrm{F}(2,8)=8.66, p=0.01$, $n=5$ rats; Figure 3a). L-655,708 had no significant effect on the time rats spent in the interaction zone in the targetabsent condition after either CUS $(\mathrm{F}(2,23)=1.484, p=0.248)$ or CRS $(F(1,10)=0.971, p=0.348)$, and it had no significant effect in unstressed animals (Supplementary Figure).
Similarly, L-655,708 had no effect on either the total number of line crossings (Figure $3 \mathrm{~b}$ ) or center line crossings (Figure 3c) in an open-field test $30 \mathrm{~min}$ after injection ( $n=6$ rats each), indicating that it did not induce nonspecific effects on locomotor behavior or anxiety.

We also tested the effects of a second, chemically distinct $\alpha 5$-preferring negative allosteric modulator, MRK-016, at a dose of $3 \mathrm{mg} / \mathrm{kg}$. This dose should produce roughly $80 \%$ occupancy of $\alpha 5$-containing $\mathrm{GABA}_{\mathrm{A}} \mathrm{Rs}$ (Atack et al, 2009). Within $24 \mathrm{~h}$, a single injection of MRK-016 restored sucrose preference $(\mathrm{F}(3,33)=20.63, p<0.0001, n=12$ rats; Figure $4 \mathrm{a}$ and $\mathrm{b})$ and social interaction $(\mathrm{F}=(2,14)=11.84$, $p=0.000978, n=8$ rats; Figure $4 c$ ) in rats subjected to CRS. Sucrose preference and social interaction ratios remained statistically indistinguishable from baseline values even 7 days after the injection of MRK-016, despite continued CRS.

Taken together, these data show that two $\alpha 5$-selective negative allosteric modulators reversed chronic stressinduced depressive-like behavioral changes in $<24 \mathrm{~h}$ in a model-independent manner. The response of individual animals to chronic stress and the two compounds in both the sucrose preference and social interaction tests were highly correlated $(r=0.69 ; t(25)=4.781, p<0.0001 ;$ Figure 5). Neither compound produced any detectable change in the behavior of unstressed animals in these tests.

\section{Rapid Reversal of Stress-Induced Weakening of Excitatory Synaptic Transmission by L-655,708}

Chronic stress induces a reduction in excitatory synaptic transmission in many cortico-mesolimbic nuclei, including TA-CA1 synapses in the hippocampus (Kallarackal et al, 2013). Chronic, but not acute, administration of fluoxetine 


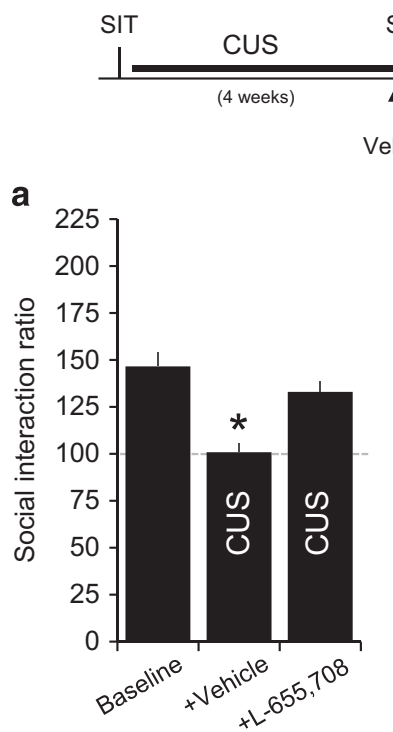

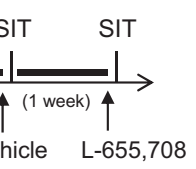

b

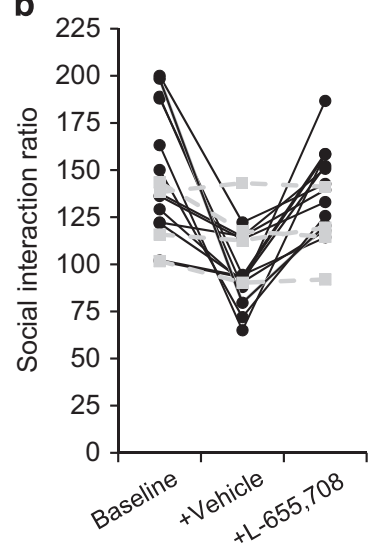

c

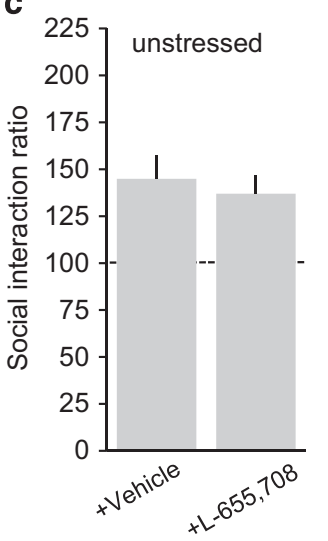

d

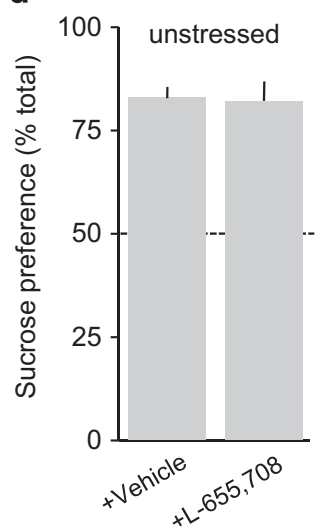

Figure 2 L-655,708 rapidly reverses loss of social interaction behaviors after chronic unpredictable stress (CUS) but does not affect hedonic behavior in unstressed rats. Quantification of results from the social interaction test (SIT) at three time points: before CUS, after 4 weeks of CUS and a vehicle injection given $24 \mathrm{~h}$ earlier, and after an additional week of CUS and an injection of L-655,708 given $24 \mathrm{~h}$ earlier. (a) Mean social interaction ratio differed significantly in the CUS+vehicle group compared with all other groups $(F(2,34)=15, p<0.000 \mid$; * $p<0.05$ vs other groups, Tukey's test, $n=\mid 8$ rats). (b) Analysis of individual animals revealed that I 4 of 18 animals displayed robust responses to CUS and L-655,708 (black). The four rats that failed to respond to L-655,708 appeared largely resilient to the effects of CUS (gray symbols). Unstressed controls were also given vehicle and L-655,708 injections at the same time points. Neither injection produced a significant change in social interaction (c) or sucrose preference (d).
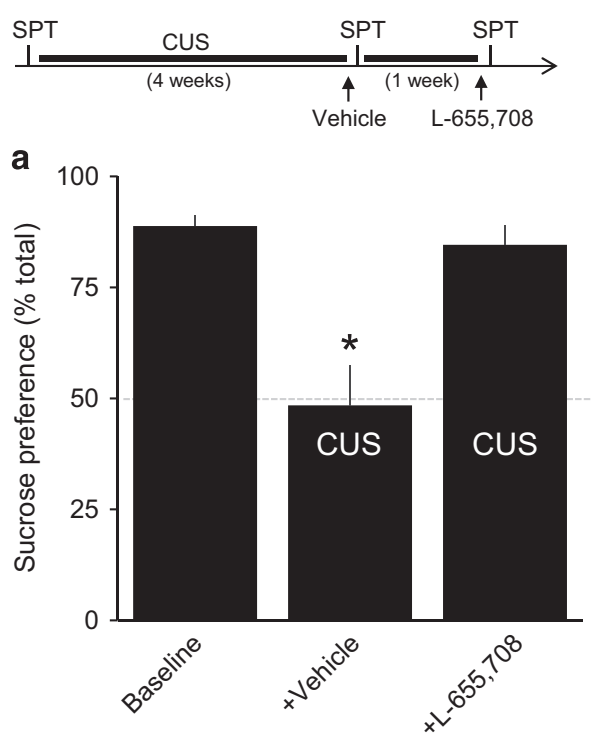
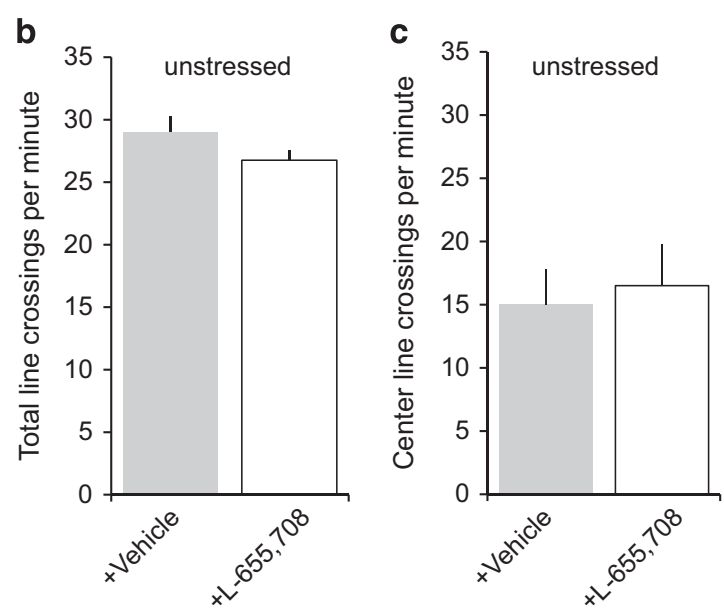

Figure 3 L-655,708 rapidly reverses loss of sucrose preference after chronic unpredictable stress (CUS) but does not affect behavior in the open-field test. (a) Quantification of results from sucrose preference tests at three time points: before CUS, after 4 weeks of CUS and a vehicle injection given $24 \mathrm{~h}$ earlier, and after an additional week of CUS and an injection of L-655,708 given $24 \mathrm{~h}$ earlier. Mean sucrose preference differed significantly in the CUS+vehicle group compared with all other groups $(F(2,8)=8.66, p=0.0$ I, Tukey's test, $n=5$ rats). $* p<0.05$ compared with pre-CUS baseline, Bonferroni post hoc test. In the open-field test, there was no significant difference between unstressed rats given an injection of vehicle or L-655,708 ( $n=6$ rats each) 30 min earlier in either total number of line crossings (b), an indicator of locomotor activity, or in crossings to the center of the arena (c), an indicator of anxiety.

restores their strength with a time course that is comparable with behavioral restoration (Cai et al, 2013). We therefore examined TA-CA1 synaptic transmission to ask whether L-655,708 would reverse this stress-induced synaptic phenotype as rapidly as it reversed stress-induced behavioral changes.
We used extracellular electrophysiological recording of fEPSPs at TA-CA1 synapses in SLM of area CA1 in brain slices prepared from unstressed rats, rats subjected to 10 days of CRS and given a vehicle injection $24 \mathrm{~h}$ earlier, and rats subjected to 10 days of CRS and given an L-655,708 injection $24 \mathrm{~h}$ earlier $(0.7 \mathrm{mg} / \mathrm{kg}$, i.p.). These were the same rats used 

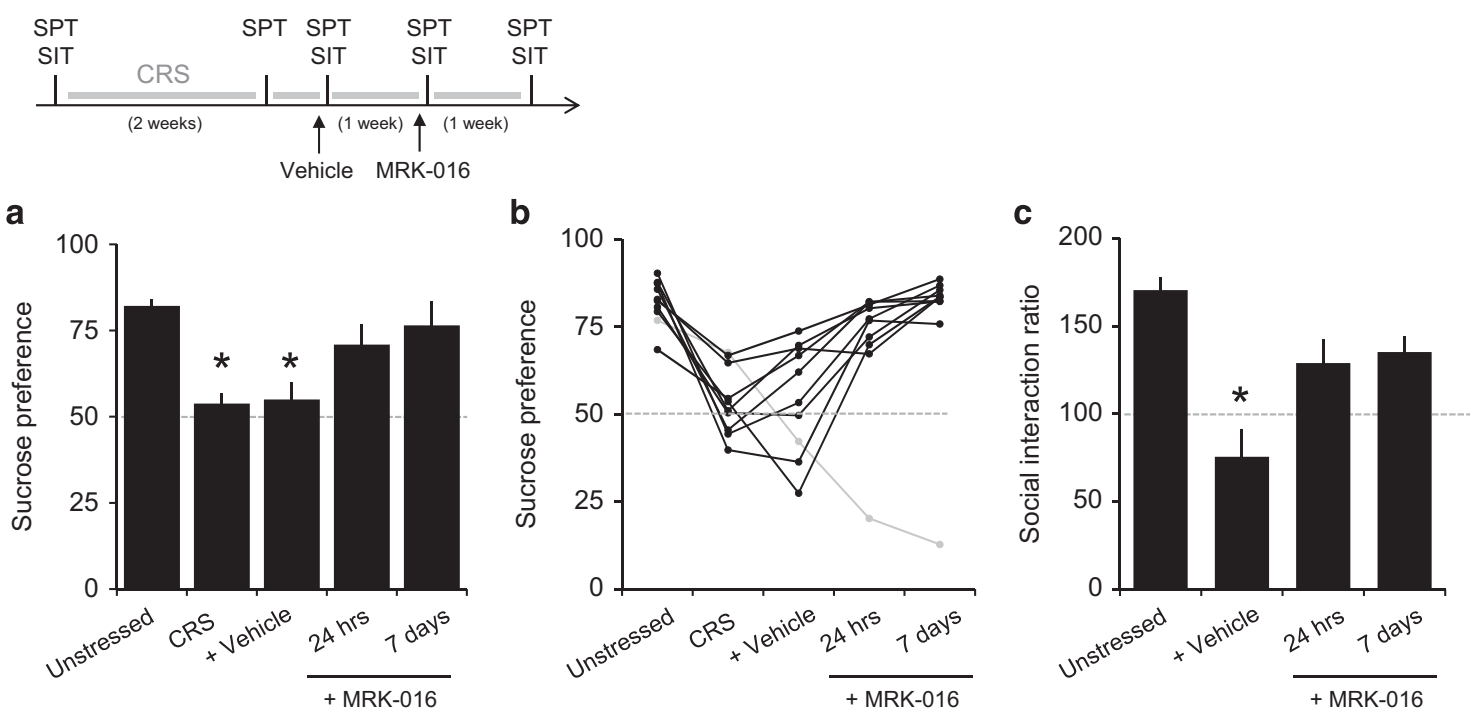

Figure 4 MRK-016 rapidly reverses loss of sucrose preference (SPT) and social interaction (SIT) behaviors after chronic restraint stress (CRS). (a) Quantification of results from one group of rats in the sucrose preference test at five time points: baseline, after 2 weeks of CRS, $24 \mathrm{~h}$ after an additional 3 days of CRS and $24 \mathrm{~h}$ after injection of vehicle, after one week of CRS and $24 \mathrm{~h}$ after an injection of MRK-0 6 (3 mg/kg), and in the same animals after an additional week of CRS and 7 days after the injection of MRK-0 16. Mean sucrose preference differed significantly following vehicle injection compared with all other groups $(F(3,33)=20.63, p<0.0001, n=12$ rats). $* p<0.05$ compared with pre-CUS baseline, Tukey's post hoc test). (b) Results in individual animals for the full experiment. (c) Quantification of results from one group of rats in the social interaction test at four time points: baseline, after 2 weeks of CRS and $24 \mathrm{~h}$ after injection of vehicle, after I week of CRS and $24 \mathrm{~h}$ after an injection of MRK-0 6 (3 mg/kg), and in the same animals after an additional week of CRS and 7 days after the injection of MRK-016. Mean social interaction ratios differed significantly following vehicle injection compared with all other groups $(F=(2,14)=11.84, p=0.0009, n=8$ rats $) .{ }^{*} p<0.05$ compared with pre-CUS baseline, Tukey's post hoc test $)$

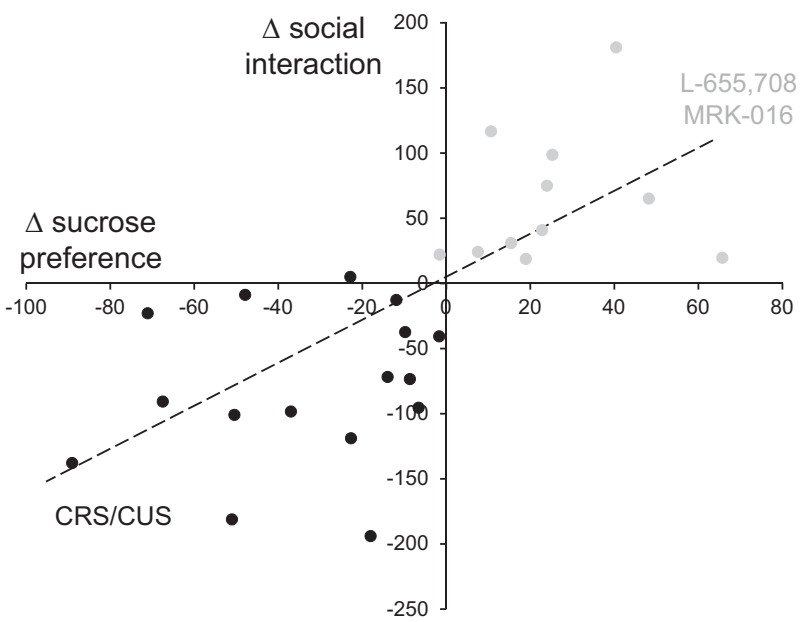

Figure 5 Correlation of changes in social interaction and sucrose preference behaviors after chronic stress and after administration of $\alpha 5$ preferring negative allosteric modulators. Changes from baseline responses in the social interaction and sucrose preference tests in response to either chronic restraint stress (CRS) or chronic unpredictable stress (CUS) in individual rats are shown in black. Changes from CRS/CUS responses in the social interaction and sucrose preference tests in response to injection of either L-655,708 or MRK-016 $24 \mathrm{~h}$ earlier in individual rats are shown in gray. There was a strong correlation for both behavioral outcomes (linear fit in black; $r=0.69 ; t(25)=4.78 \mathrm{I}, p=0.000 \mathrm{I} ; n=27)$.

for the behavioral analyses in Figure 1. fEPSPs were recorded in ACSF lacking added $\mathrm{Mg}^{2+}$ so as to unblock NMDA receptors. We first quantified the slope of the AMPAR component of the fEPSP elicited over a range of stimulation intensities as a function of the amplitude of the fiber volley (FV), a measure of the number of synapses activated. We then applied DNQX to block AMPAR-mediated transmission and elicited a series of NMDAR-mediated responses over the same range of stimulation intensities, as in our previous study (Kallarackal et al, 2013).

We observed a decrease in the slope of the AMPARmediated component of the fEPSP across all stimulation intensities in slices from rats subjected to CRS and given a vehicle injection, compared with slices from unstressed rats and slices from rats subjected to CRS and given an L-655,708 injection $(\mathrm{F}(2,17)=3.675, p=0.047 ; n=5$ unstressed, 8 CRS +vehicle, 7 CRS+L655,708; Figure 6a and b). There was no corresponding difference in the slope of the NMDA component of the fEPSP under these conditions ( $F$ $(2,17)=0.549, p=0.588$; Figure $3 \mathrm{a}$ and $\mathrm{b})$. We also computed an AMPA:NMDA ratio for each slice using the slope of the response elicited when the $\mathrm{FV}$ was $\sim 0.2 \mathrm{mV}$ in amplitude before and after application of DNQX. The AMPA:NMDA ratio was significantly higher in slices from CRS rats injected with L-655,708 $24 \mathrm{~h}$ earlier, compared with vehicle-treated animals subjected to CRS ( $p<0.05$ LSD post hoc), and was not different than responses in tissue from unstressed rats ( $\mathrm{F}$ $(2,17)=4.345, p=0.03$; Figure $6 c)$.

These results replicate our earlier observations that AMPAR-mediated signaling, but not NMDAR-mediated signaling, is impaired by chronic stress at TA-CA1 synapses and we now demonstrate that this impairment can be reversed rapidly by treatment with L-655,708. We conclude that the behavioral antidepressant efficacy of L-655,708 is 
a

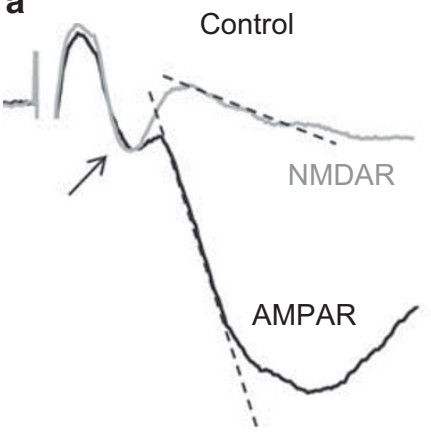

b

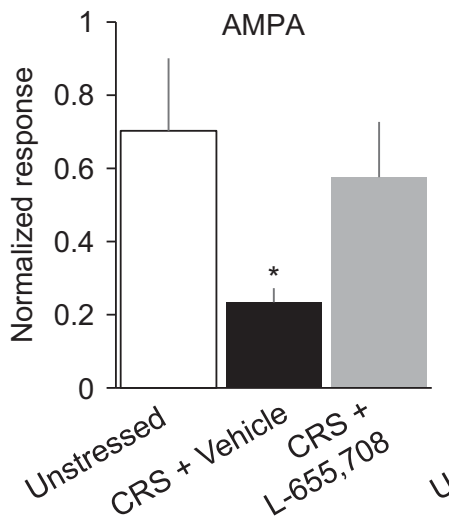

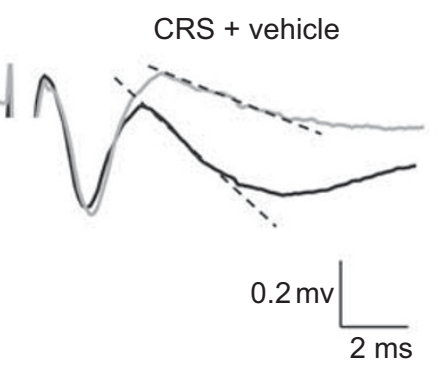

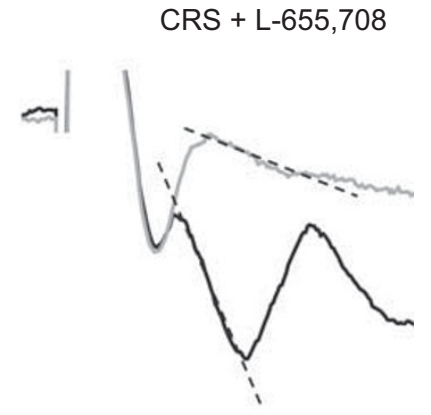

C

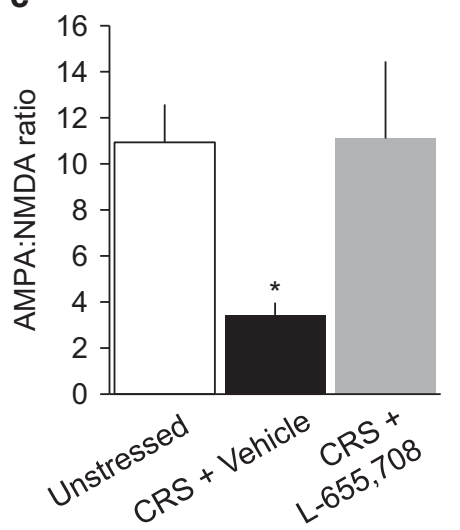

Figure 6 L-655,708 rapidly reverses stress-induced weakening of AMPAR-mediated synaptic transmission in TA-CAI synapses of the rat hippocampus. (a) Representative traces showing the AMPAR- and NMDAR-mediated components of the fEPSP, recorded extracellularly in SLM of area CAI in response to simulation of TA afferents in saline lacking added $\mathrm{Mg}^{2+}$. Traces are shown before (black) and after (gray) addition of $50 \mu M$ DNQX to block AMPARs. Traces were recorded from slices taken from unstressed controls (left) and rats subjected to 10 days of CRS then given an injection $24 \mathrm{~h}$ earlier of either vehicle solution (middle) or L-655,708 (right). (b) The mean slope of the relationship between AMPAR- (left) and NMDAR-mediated response (right) and FV amplitude over a range of stimulation intensities from the three groups of animals. The slope of the AMPAR-mediated responses was decreased significantly in slices from vehicle-treated CRS rats (red) compared with slices from unstressed (blue) or L-655,708-treated CRS rats (green) across the range of stimulation intensities (I-Way ANOVA, F(2,I 1) =3.675, $p=0.047 ; n=5$ unstressed, 8 CRS+vehicle, 7 CRS+L-655,708; * $p<0.05$, LSD post hoc test). There were no significant differences in NMDAR-mediated responses ( $\mathrm{I}$-Way analysis of variance (ANOVA), $\mathrm{F}(2,17)=0.549, p=0.588$ ). (c) AMPA:NMDA ratios were computed from the initial slopes of the responses in each slice before and after application of DNQX (shown by dotted lines in a). AMPA:NMDA ratios were decreased significantly in slices from vehicle-treated CRS rats compared with slices from either unstressed or L-655,708-treated CRS rats (one-way ANOVA $F(2,17)=4.345 p=0.03 ; n=5$ unstressed, 8 CRS+vehicle, 7 CRS+L-655,708; * $p<0.05$ compared with unstressed and CRS+L-655,708, LSD post hoc test). A full color version of this figure is available at the Neuropsychopharmacology journal online.

associated with a restoration of excitatory neurotransmission at this stress-sensitive synapse.

\section{Rapid Reversal of Stress-Induced Downregulation of GluA1 Expression by L-655,708}

Restoration of stress-impaired AMPAR-mediated transmission produced by treatment with either chronic SSRIs (Kallarackal et al, 2013) or ketamine (Li et al, 2011) is associated with an increase in the expression of the GluA1 subunit of the AMPAR. We next asked whether L-655,708 would also restore GluA1 expression as rapidly as it reverses the stress-induced behavioral and synaptic phenotypes.

SLM tissue was harvested from slices taken from unstressed rats, rats subjected to 10 days of CRS and given a vehicle injection $24 \mathrm{~h}$ earlier, and rats subjected to 10 days of CRS and given an injection of L-655,708 $24 \mathrm{~h}$ earlier $(0.7 \mathrm{mg} / \mathrm{kg}$, i.p.). These were the same rats used for Figure 1. As we have reported previously for CUS, rats subjected to CRS and injected with vehicle displayed a significantly lower level of GluA1 protein in SLM as compared with unstressed control rats (Kruskal-Wallis H test: $\chi^{2}(2)=10.62, p=0.0049$; $n=6$ unstressed rats, 6 CRS+vehicle, 8 CRS+L-655,708; Figure 7). In contrast, stressed rats injected with L-655,708 $24 \mathrm{~h}$ earlier displayed levels of GluA1 in SLM that were not significantly different than levels in unstressed controls.

These results demonstrate that the stress-induced decrease in GluA1 protein expression, which was correlated with both weakened excitatory synaptic transmission at TA-CA1 synapses and altered hedonic behaviors, was reversed rapidly by treatment with L-655,708. $\alpha 5$-subunit-selective negative allosteric modulators thus displaying antidepressant efficacy at behavioral, electrophysiological, and molecular end points.

\section{DISCUSSION}

We have discovered that two negative allosteric modulator of GABARs that act as a partial inverse agonists at the benzodiazepine binding site and are highly selective for receptors containing $\alpha 5$-subunits, L-655,708 and MRK-016, reverse the behavioral and synaptic phenotypes produced by 

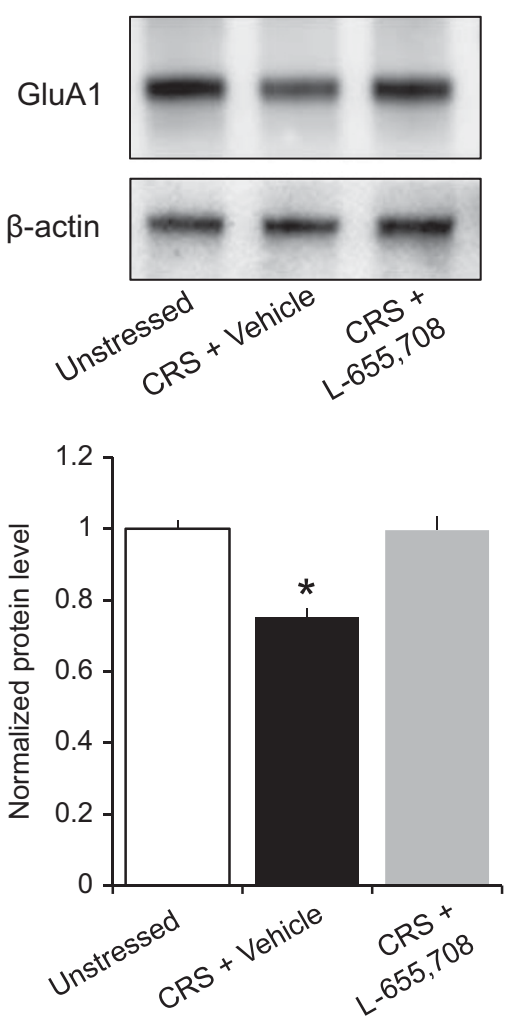

Figure 7 L-655,708 rapidly reverses stress-induced decreases in GluA I expression at TA-CAI synapses of the rat hippocampus. (Upper panel) Representative western blots of GluAI and $\beta$-actin protein levels in SLM samples from unstressed rats (left) and rats subjected to 10 days of CRS then given an injection $24 \mathrm{~h}$ earlier of either vehicle solution (middle) or L-655,708 (right). (Lower panel) GluAI expression, normalized to $\beta$-actin levels, was decreased significantly in tissue from vehicle-treated CRS rats (red) compared to tissue from unstressed (blue) or L-655,708-treated CRS rats (green)(Kruskal-Wallis $H$ test: $\chi^{2}(2)=10.62, \quad p=0.0049 ; n=6$ unstressed, 6 CRS+vehicle, 8 CRS+L-655,708; *p $<0.05$ compared with unstressed and CRS+L-655,708, post hoc Mann-Whitney U-test). A full color version of this figure is available at the Neuropsychopharmacology journal online.

two different chronic stress paradigms within $24 \mathrm{~h}$ of a single systemic administration. These effects persisted for several days after a single injection. At the concentrations used in our study, these compounds do have measurable binding to non- $\alpha 5$-subunits, thus we cannot formally exclude the possibility that their effects are mediated by $\mathrm{GABA}_{\mathrm{A}} \mathrm{Rs}$ containing other alpha subunits.

The motivated, appetitive behaviors assayed in the social interaction and sucrose preference tests test the hedonic properties of two distinct stimuli, food, and sociality. In both the sucrose preference and social interaction tests, rats must respond in an active manner to display the high levels of sucrose preference and social interaction that are normally observed. Chronic stress is known to decrease the rewarding properties of a variety of natural and unnatural stimuli in rodents, including their high preference for palatable sucrose-containing solution (Pothion et al, 2004) and the naturally rewarding value of social interactions (Zelena et al, 1999; Berton et al, 2006). The loss of the rewarding properties of these stimuli is considered to be analogous to anhedonia, or the inability to experience reward, a core symptom of human depression. Importantly, normal behavior in both the sucrose preference test (Rygula et al, 2006) and social interaction test (Berton et al, 2006) is restored with chronic, but not acute, administration of SSRIs, thus providing a strong predictive indication of the potential human antidepressant efficacy of $\alpha 5$-selective negative allosteric modulators.

\section{$\alpha 5$-Containing $\mathrm{GABA}_{\mathrm{A}}$ Receptors as an Antidepressant Drug Target}

$\mathrm{GABA}_{\mathrm{A}}$ receptors are heteropentameric ion channels, most commonly containing $\alpha$-, $\beta$-, and $\gamma$-subunits in a $2: 2: 1$ stoichiometry (Sieghart and Sperk, 2002). The interface between a $\gamma 2$-subunit and an $\alpha$-subunit forms the binding site for benzodiazepines, a site of allosteric modulation that alters channel gating and $\mathrm{GABA}_{\mathrm{A}} \mathrm{R}$ function. In addition to benzodiazepine agonists (positive modulators), there are inverse agonists that act at the same site to decrease $\mathrm{GABA}_{\mathrm{A}}$ receptor function (negative modulators). The molecular identity of the $\alpha$-subunit in the benzodiazepine binding site determines its pharmacological profile. $\mathrm{GABA}_{\mathrm{A}}$ Rs containing $\alpha 1$-subunits mediate the sedative and amnestic effects of benzodiazepines preferentially, whereas $\mathrm{GABA}_{\mathrm{A}} \mathrm{Rs}$ containing $\alpha 2$ - and $\alpha 3$-subunits mediate their anxiolytic effects (Rudolph et al, 1999; Möhler et al, 2002). Partial inverse agonists with low affinity for this binding site offer the potential advantage of a wider therapeutic concentration range and a lower likelihood of producing negative side effects, such as anxiety or epileptiform discharge.

The $\alpha 5$-subunit mRNA is abundant in pyramidal cells in the hippocampus and deep layers of the neocortex, and $\alpha 5$ containing $\mathrm{GABA}_{\mathrm{A}} \mathrm{Rs}$ are localized at synaptic and extrasynaptic sites in the dendrites (Fritschy and Möhler, 1995; Wainwright et al, 2000; Serwanski et al, 2006). $\alpha 5$-containing $\mathrm{GABA}_{\mathrm{A}}$ Rs mediate tonic (Caraiscos et al, 2004) and slow phasic (Prenosil et al, 2006; Zarnowska et al, 2009) inhibition and lower the excitability of pyramidal cells (Bonin et al, 2007), so negative allosteric modulators of $\alpha 5$-containing $\mathrm{GABA}_{\mathrm{A}} \mathrm{Rs}$ should promote coherent activity (Hajós et al, 2004; Towers et al, 2004). Drugs targeting these receptors are thus an attractive means to selectively alter activity within cortico-mesolimbic circuits without altering activity in other circuits. Indeed, deletion of the $\alpha 5$-gene alters learning in hippocampal-dependent tasks but not hippocampalindependent ones (Collinson et al, 2002; Crestani et al, 2002). Interestingly, $\alpha 5$-subunits are upregulated in mice after chronic stress (Matsumoto et al, 2007), suggesting a potential role for the $\alpha 5$-subunit in the cognitive deficits associated with chronic stress and depression.

\section{Mechanisms of L-655,708 Action}

Our observation that L-655,708 rapidly restores pathologically weakened AMPAR-mediated excitatory transmission at TA-CA1 synapses of the hippocampus suggests a likely mechanism by which L-655,708 exerts its antidepressant efficacy in behavioral testing. SSRIs (Cai et al, 2013), ketamine (Autry et al, 2011; Li et al, 2010), and L-655,708 all enhance excitatory synaptic strength at multiple sites within the cortico-mesolimbic reward circuitry, thereby providing strong support for an association between the 
restoration of excitatory synaptic strength and the reversal of depressive behavioral phenotypes (Duman, 2014; Thompson et al, 2015). TA-CA1 synapses are not uniquely sensitive to stress or responsive to antidepressants, but they do serve as a convenient archetype of stress-induced changes that are likely occurring at many synapses in the cortico-mesolimbic reward circuitry (Lim et al, 2012; Yuen et al, 2012). The net effect of this weakening is likely to be a dysfunction in processing of rewarding stimuli, which may underlie common symptoms of depression, such as anhedonia (Nestler and Carlezon, 2006). Restoration of the strength of these synapses by effective antidepressants should restore normal responses to rewarding stimuli (Belujon and Grace, 2014).

Acute administration of ketamine improves mood and reduces depressive symptoms within 1-2 h in humans and these effects persist for up to 2 weeks. Similarly, ketamine restores sucrose preference and novelty suppressed feeding behaviors rapidly $(24 \mathrm{~h})$ in chronically stressed animals (Li et al, 2011). Ketamine's therapeutic effects are induced during the brief period $(\sim 1-2 \mathrm{~h})$ when it is present in the brain at sufficient concentrations to inhibit NMDARs, triggering relief of symptoms that persist for days after it is cleared from the body. During this induction phase, ketamine may preferentially reduce excitation of GABAergic inhibitory interneurons (Dwyer and Duman, 2013; Farber et al, 1998; Homayoun and Moghaddam, 2007), thereby producing a mild disinhibition of the neuronal population and increased activity in the hippocampus, entorhinal cortex, NAc, and PFC, as observed in rodents (eg, Kittelberger et al, 2012; Middleton et al, 2008; Hunt et al, 2011; Caixeta et al, 2013) and in humans (Cornwell et al, 2012; Driesen et al, 2013). This activity is accompanied by a neurochemically detectable surge of glutamate release in the PFC and NAc (Lorrain et al, 2003; Moghaddam et al, 1997; Razoux et al, 2007). The $\alpha 5$-selective negative allosteric modulators also produce mild disinhibition by impairing $\mathrm{GABA}_{\mathrm{A}} \mathrm{R}$ channel function, and should therefore also trigger an increased coherence in oscillatory activity, as has been observed following injection of nonselective negative allosteric modulators (Hajós et al, 2004).

We suggest that the ability of both $\mathrm{GABA}_{\mathrm{A}} \mathrm{R}$ negative allosteric modulators and ketamine to promote activity accounts for their shared antidepressant efficacy because such activity strengthens excitatory synapses via convergence onto common activity-dependent signaling pathways. Potential activity-dependent processes include an increase in BDNF signaling, activation of mTOR signaling, and protein synthesis (Li et al, 2010; 2011; Autry et al, 2011). An increase in coherent circuit activity is also likely to promote the induction of long-term potentiation (eg, Huerta and Lisman, 1993). All of these activity-dependent processes have been shown to strengthen excitatory synapses. Indeed, we have observed that L-655,708 administration triggers a rapid increase in GluA1 protein levels in the distal dendrites of CA1 pyramidal cells, coincident with an increase in AMPARmediated synaptic excitation. Interestingly, chronic, but not acute, administration of SSRIs also promotes GluA1 protein levels in this same region (Kallarackal et al, 2013), which is densely innervated with serotonergic terminals.

\section{Therapeutic Potential}

Because disinhibition promotes induction of long-term potentiation, the presumptive cellular basis of memory, negative allosteric modulators of $\mathrm{GABA}_{\mathrm{A}} \mathrm{Rs}$ containing $\alpha 5$ subunits have been developed as cognitive enhancers (Ballard et al, 2009; Quirk et al, 1996; Atack et al, 2006; 2009). Unlike nonselective negative allosteric modulators, these compounds are not anxiogenic, hallucinogenic, or epileptogenic in humans (Atack et al, 2009).

Although SSRIs are reasonably safe and well tolerated, and are not addictive, they are effective in only a subset of patients and only after a delay of weeks to months. Ketamine, on the other hand, exerts a rapid antidepressant action in the majority of patients, but its therapeutic utility is extremely limited due to its dissociative and anesthetic properties, as well as its potential for abuse and overdose. L-655,708 and MRK-016 reversed stress-induced behavioral changes and restored AMPAR-mediated excitatory synaptic strength in two well-validated rodent models of antidepressant efficacy, like SSRIs and ketamine. Because these effects were induced within $24 \mathrm{~h}$ of a single systemic injection, we suggest that negative allosteric modulators acting on $\alpha 5$-subunit-containing $\mathrm{GABA}_{\mathrm{A}}$ Rs represent a novel, rapidly acting, effective, and clinically viable treatment for human depression.

\section{FUNDING AND DISCLOSURE}

This work was supported by grants R01 MH086828 (SMT), T32 GM008181 (AMVD), T32 NS063391 (MDK), and T32 NS007375 (TAL). The authors declare no conflict of interests.

\section{ACKNOWLEDGMENTS}

We thank Drs Angy Kallarackal and Xiang Cai for their contributions to the formulation of this hypothesis and Drs Todd Gould and Robert Schwarcz for their comments on the manuscript. AM Van Dyke and MD Kvarta are shareholders in Asulon Therapeutics, Inc. AM Van Dyke, MD Kvarta, and SM Thompson have filed a patent application covering the use of alpha5-selective negative allosteric modulators as fast acting antidepressants.

\section{REFERENCES}

Abdallah CG, Sanacora G, Duman RS, Krystal JH (2014). Ketamine and rapid-acting antidepressants: a window into a new neurobiology for mood disorder therapeutics. Annu Rev Med 66: 509-523.

Atack JR, Alder L, Cook SM, Smith AJ, McKernan RM (2005). In vivo labelling of $\alpha 5$ subunit-containing $\mathrm{GABA}_{\mathrm{A}}$ receptors using the selective radioligand $\left[{ }^{3} \mathrm{H}\right] \mathrm{L}-655,708$. Neuropharmacology 49: 220-229.

Atack JR, Bayley PJ, Seabrook GR, Wafford KA, McKernan RM, Dawson GR (2006). L-655,708 enhances cognition in rats but is not proconvulsant at a dose selective for $\alpha 5$-containing $\mathrm{GABA}_{\mathrm{A}}$ receptors. Neuropharmacology 51: 1023-1029.

Atack JR, Maubach KA, Wafford KA, O'Connor D, Rodrigues AD, Evans DC et al (2009). In vitro and in vivo properties of 3-tertButyl-7-(5-methylisooxazol-3-yl)-2-(1-methyl-1H-1,2,4-triazol-5ylmethoxy)-pyrazolo[1,5-d]-[1,2,4] triazine (MRK-016), a GA$\mathrm{BA}_{\mathrm{A}}$ receptor $\alpha 5$ subtype-selective inverse agonist. J Pharmacol Exp Ther 331: 470-484. 
Autry AE, Nosyreva E, Na ES, Los MF, Cheng PF, Kavalali ET et al (2011). NMDA receptor blockade at rest triggers rapid behavioral antidepressant responses. Nature 475: 91-95.

Ballard T, Knoflach F, Prinssen E, Borroni E, Vivian JA, Basile J et al (2009). RO4938581, a novel cognitive enhancer acting at $\mathrm{GABA}_{\mathrm{A}} \alpha 5$ subunit-containing receptors. Psychopharmacology 202: 207-223.

Belujon P, Grace AA (2014). Restoring mood balance in depression: ketamine reverses deficit in dopamine-dependent synaptic plasticity. Biol Psychiatry 76: 927-936.

Berman RM, Cappiello A, Anand A, Oren DA, Heninger GR, Charney DS et al (2000). Antidepressant effects of ketamine in depressed patients. Biol Psychiatry 47: 351-354.

Berton O, McClung CA, Dileone RJ, Krishnan V, Renthal W, Russo SJ et al (2006). Essential role of BDNF in the mesolimbic dopamine pathway in social defeat stress. Science 311: 864-868.

Bonin RP, Martin LJ, MacDonald JF, Orser BA (2007). $\alpha 5$ GABAA receptors regulate the intrinsic excitability of mouse hippocampal pyramidal neurons. J Neurophysiology 98: 2244-2254.

Cai X, Kallarackal AJ, Kvarta MD, Goluskin S, Gaylor K, Bailey AM et al (2013). Local potentiation of excitatory synapses by serotonin and its alteration in rodent models of depression. Nat Neurosci 16: 464-472.

Caixeta FV, Cornelio AM, Scheffer-Teixeira R, Ribeiro S, Tort ABL (2013). Ketamine alters oscillatory coupling in the hippocampus. Nat Sci Rep 3: 2348.

Caraiscos VB, Elliott EM, You-Ten KE, Cheng VY, Belelli D, Newell JG et al (2004). Tonic inhibition in mouse hippocampal CA1 pyramidal neurons is mediated by $\alpha 5$ subunit-containing $\gamma$-aminobutyric acid type A receptors. Proc Natl Acad Sci USA 101: 3662-3667.

Collinson N, Kuenzi FM, Jarolimek W, Maubach KA, Cothliff R, Sur C et al (2002). Enhanced learning and memory and altered GABAergic synaptic transmission in mice lacking the alpha 5 subunit of the $\mathrm{GABA}_{\mathrm{A}}$ receptor. J Neurosci 22: 5572-5580.

Cornwell B, Salvadore G, Furey M (2012). Synaptic potentiation is critical for rapid antidepressant response to ketamine in treatment-resistant major depression. Biol Psychiatry 72: 555-561.

Crestani F, Keist R, Fritschy JM, Benke D, Vogt K, Prut L et al (2002). Trace fear conditioning involves hippocampal alpha5 GABA $_{\mathrm{A}}$ receptors. Proc Natl Acad Sci USA 99: 8980-8985.

Driesen NR, McCarthy G, Bhagwagar Z, Bloch MH, Calhoun VD, D'Souza DC et al (2013). The impact of NMDA receptor blockade on human working memory-related prefrontal function and connectivity. Neuropsychopharmacology 38: 2613-2622.

Duman RS (2014). Neurobiology of stress, depression and rapid acting antidepressants: remodeling synaptic connections. Depress Anxiety 31: 291-296.

Duman RS, Voleti B (2012). Signaling pathways underlying the pathophysiology and treatment of depression: novel mechanisms for rapid-acting agents. Trends Neurosci 35: 47-56.

Dwyer JM, Duman RS (2013). Activation of mammalian target of rapamycin and synaptogenesis: role in the actions of rapid-acting antidepressants. Biol Psychiatry 73: 1189-1198.

Farber NB, Newcomer JW, Olney JW (1998). The glutamate synapse in neuropsychiatric disorders. Focus on schizophrenia and Alzheimer's disease. Prog Brain Res 116: 421-437.

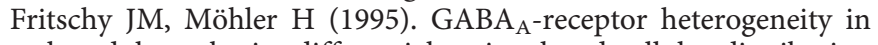
the adult rat brain: differential regional and cellular distribution of seven major subunits. J Comp Neurol 1359: 154-194.

Gaynes B, Warden D (2009). What did STAR* D teach us? Results from a large-scale, practical, clinical trial for patients with depression. Psychiatry Serv 60: 1439-1445.

Hajós M, Hoffmann WE, Orbán G, Kiss T, Erdi P (2004). Modulation of septo-hippocampal theta activity by $\mathrm{GABA}_{\mathrm{A}}$ receptors: an experimental and computational approach. Neuroscience 126: 599-610.

Homayoun H, Moghaddam B (2007). NMDA receptor hypofunction produces opposite effects on prefrontal cortex interneurons and pyramidal neurons. J Neurosci 27: 11496-11500.

Huerta PT, Lisman JE (1993). Heightened synaptic plasticity of hippocampal CA1 neurons during a cholinergically induced rhythmic state. Nature 364: 723-725.

Hunt MJ, Falinska M, Łeski S, Wójcik DK, Kasicki S (2011). Differential effects produced by ketamine on oscillatory activity recorded in the rat hippocampus, dorsal striatum and nucleus accumbens. J Psychopharmacol 25: 808-821.

Kallarackal AJ, Kvarta MD, Cammarata E, Jaberi L, Cai X, Bailey AM et al (2013). Chronic stress induces a selective decrease in AMPA receptor-mediated synaptic excitation at hippocampal temporoammonic-CA1 synapses. J Neurosci 33: 15669-15674.

Kavalali ET, Monteggia LM (2012). Synaptic mechanisms underlying rapid antidepressant action of ketamine. Am J Psychiatry 169: $1150-1156$.

Kittelberger K, Hur EE, Sazegar S, Keshavan V, Kocsis B (2012). Comparison of the effects of acute and chronic administration of ketamine on hippocampal oscillations: relevance for the NMDA receptor hypofunction model of schizophrenia. Brain Struct Funct 217: 395-409.

Li N, Lee B, Liu RJ, Banasr M, Dwyer JM, Iwata M et al (2010). mTOR-dependent synapse formation underlies the rapid antidepressant effects of NMDA antagonists. Science 329: 959-964.

Li N, Liu RJ, Dwyer JM, Banasr M, Lee B, Son H et al (2011). Glutamate $\mathrm{N}$-methyl-D-aspartate receptor antagonists rapidly reverse behavioral and synaptic deficits caused by chronic stress exposure. Biol Psychiatry 69: 754-761.

Lim BK, Huang KW, Grueter BA, Rothwell PE, Malenka RC (2012). Anhedonia requires MC4R-mediated synaptic adaptations in nucleus accumbens. Nature 487: 183-189.

Lorrain DS, Baccei CS, Bristow LJ, Anderson JJ, Varney MA (2003). Effects of ketamine and N-methyl-D-aspartate on glutamate and dopamine release in the rat prefrontal cortex: modulation by a group II selective metabotropic glutamate receptor agonist LY379268. Neuroscience 117: 697-706.

Maeng S, Zarate CA, Du J, Schloesser RJ, McCammon J, Chen G et al (2008). Cellular mechanisms underlying the antidepressant effects of ketamine: role of alpha-amino-3-hydroxy-5-methylisoxazole-4-propionic acid receptors. Biol Psychiatry 63: 349-352.

Machado-Vieira R, Salvadore G, Diazgranados N, Zarate CA (2009). Ketamine and the next generation of antidepressants with a rapid onset of action. Pharmacol Ther 123: 143-150.

Martin LJ, Oh GH, Orser BA (2009). Etomidate targets $\alpha 5$ $\gamma$-aminobutyric acid subtype A receptors to regulate synaptic plasticity and memory blockade. Anesthesiol 111: 1025-1035.

Matsumoto K, Puia G, Dong E, Pinna G (2007). GABA receptor neurotransmission dysfunction in a mouse model of social isolation-induced stress: possible insights into a nonserotonergic mechanism of action of SSRIs in mood and anxiety disorders. Stress 10: 3-12.

McEwen BS (2000). Allostasis and allostatic load: implications for neuropsychopharmacology. Neuropsychopharmacology 22: 108-124.

Middleton S, Jalics J, Kispersky T, Lebeau FE, Roopun AK, Kopell NJ et al (2008). NMDA receptor-dependent switching between different gamma rhythm-generating microcircuits in entorhinal cortex. Proc Natl Acad Sci USA 105: 18572-18577.

Moghaddam B, Adams B, Verma A, Daly D (1997). Activation of glutamatergic neurotransmission by ketamine: A novel step in the pathway from NMDA receptor blockade. J Neurosci 17: 2921-2927.

Möhler H, Fritschy JM, Rudolph U (2002). A new benzodiazepine pharmacology. J Pharmacol Exp Ther 300: 2-8. 
Nestler EJ, Carlezon WA (2006). The mesolimbic dopamine reward circuit in depression. Biol Psychiatry 59: 1151-1159.

Pittenger C, Duman RS (2008). Stress, depression, and neuroplasticity: a convergence of mechanisms. Neuropsychopharmacology 33: 88-109.

Pothion S, Bizot J-C, Trovero F, Belzung C (2004). Strain differences in sucrose preference and in the consequences of unpredictable chronic mild stress. Behav Brain Res 155: 135-146.

Prenosil GA, Schneider Gasser EM, Rudolph U, Keist R, Fritschy JM, Vogt KE (2006). Specific subtypes of $\mathrm{GABA}_{\mathrm{A}}$ receptors mediate phasic and tonic forms of inhibition in hippocampal pyramidal neurons. J Neurophysiol 96: 846-857.

Quirk K, Blurton P, Fletcher S, Leeson P, Tang F, Mellilo D et al (1996). [ $\left.{ }^{3} \mathrm{H}\right] \mathrm{L}-655,708$, a novel ligand selective for the benzodiazepine site of $\mathrm{GABA}_{\mathrm{A}}$ receptors which contain the $\alpha 5$ subunit. Neuropharmacology 35: 1331-1335.

Razoux F, Garcia R, Léna I (2007). Ketamine, at a dose that disrupts motor behavior and latent inhibition, enhances prefrontal cortex synaptic efficacy and glutamate release in the nucleus accumbens. Neuropsychopharmacology 32: 719-727.

Rudolph U, Crestani F, Benke D, Brünig I, Benson JA, Fritschy JM et al (1999). Benzodiazepine actions mediated by specific $\gamma$ aminobutyric acid $_{A}$ receptor subtypes. Nature 401: 796-800.

Rygula R, Abumaria N, Flugge G, Hiemke C, Fuchs E, Ruther E et al (2006). Citalopram counteracts depressive-like symptoms evoked by chronic social stress in rats. Behav Pharmacol 17: 19-29.

Serwanski DR, Miralles CP, Christie SB, Mehta AK, Li X, De Blas $\mathrm{AL}$ (2006). Synaptic and nonsynaptic localization of $\mathrm{GABA}_{\mathrm{A}}$ receptors containing the $\alpha 5$ subunit in the rat brain. J Comp Neurol 499: 458-470.

Sieghart W, Sperk G (2002). Subunit composition, distribution and function of $\mathrm{GABA}_{\mathrm{A}}$ receptor subtypes. Curr Top Med Chem 2: 795-816.

Thompson SM, Kallarackal AJ, Kvarta MD, Van Dyke AM, LeGates TA, Cai X (2015). An excitatory synapse hypothesis of depression. Trends Neurosci 38: 279-294.
Towers SK, Gloveli T, Traub RD, Driver JE, Engel D, Fradley R et al (2004). Alpha 5 subunit-containing GABAA receptors affect the dynamic range of mouse hippocampal kainate-induced gamma frequency oscillations in vitro. J Physiol 559: 721-728.

Trullas R, Skolnick P (1990). Functional antagonists at the NMDA receptor complex exhibit antidepressant actions. Eur J Pharmacol 18: $1-10$

Voleti B, Navarria A, Liu RJ, Banasr M, Li N, Terwilliger R et al (2013). Scopolamine rapidly increases mammalian target of rapamycin complex 1 signaling, synaptogenesis, and antidepressant behavioral responses. Biol Psychiatry 74: 742-749.

Wainwright A, Sirinathsinghji DJ, Oliver KR (2000). Expression of $\mathrm{GABA}_{\mathrm{A}}$ receptor $\alpha 5$ subunit-like immunoreactivity in human hippocampus. Mol Brain Res 80: 228-232.

Watanabe Y, Gould E, McEwen BS (1992). Stress induces atrophy of apical dendrites of hippocampal CA3 pyramidal neurons. Brain Res 588: 341-345.

Willner P, Towell A, Sampson D, Sophokleous S, Muscat R (1987). Reduction of sucrose preference by chronic unpredictable mild stress, and its restoration by a tricyclic antidepressant. Psychopharmacology (Berl) 93: 358-364.

Yuen EY, Wei J, Liu W, Zhong P, Li X, Zhen Y (2012). Repeated stress causes cognitive impairment by suppressing glutamate receptor expression and function in prefrontal cortex. Neuron 73: 962-977.

Zarate CA, Singh JB, Carlson PJ, Brutsche NE, Ameli R, Luckenbaugh DA et al (2006). A randomized trial of an $\mathrm{N}$-methyl-D-aspartate antagonist in treatment-resistant major depression. Arch Gen Psychiatry 63: 856-864.

Zarnowska ED, Keist R, Rudolph U, Pearce RA (2009). GABA receptor alpha5 subunits contribute to GABAA,slow synaptic inhibition in mouse hippocampus. J Neurophysiol 101: 1179-1191.

Zelena D, Haller J, Halász J, Makara GB (1999). Social stress of variable intensity: physiological and behavioral consequences. Brain Res Bull 48: 297-302.

Supplementary Information accompanies the paper on the Neuropsychopharmacology website (http://www.nature.com/npp) 